\title{
Correction to: The interplay between HIF-1a and noncoding RNAs in cancer
}

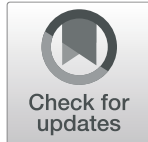

Xiafeng Peng ${ }^{1,2+}$, Han Gao ${ }^{3+}$, Rui Xu ${ }^{4}$, Huiyu Wang ${ }^{1}$, Jie Mei ${ }^{1 *}$ and Chaoying Liu ${ }^{1 *}$

\section{Correction to: J Exp Clin Cancer Res \\ https://doi.org/10.1186/s13046-020-1535-y}

In the original publication of this manuscript [1], Fig. 2 contains incorrect labels and feedback loops. The revised version of Fig. 2 is shown below.

In the first paragraph of the 'Negative feedback loop between HIF- $1 \alpha$ and ncRNA' section, there are two instances of 'miR-439'; these should instead read 'miR429'.

\section{Author details}

'Department of Oncology, Wuxi People's Hospital Affiliated to Nanjing Medical University, 299 Qingyang Road, Wuxi 214023, China. ${ }^{2}$ The First Clinical Medicine School, Nanjing Medical University, Nanjing 211166, China. ${ }^{3}$ Wuxi School of Medicine, Jiangnan University, Wuxi 214122, China. ${ }^{4}$ School of Basic Medical Sciences, Nanjing Medical University, Nanjing 211166, China.

Published online: 03 March 2020

\section{Reference}

1. Peng, et al. J Exp Clin Cancer Res. 2020;39:27.

The original article can be found online at https://doi.org/10.1186/s13046020-1535-y

*Correspondence: meijie1996@njmu.edu.cn; liuchaoying666@163.com

${ }^{+}$Xiafeng Peng and Han Gao contributed equally to this work.

'Department of Oncology, Wuxi People's Hospital Affiliated to Nanjing

Medical University, 299 Qingyang Road, Wuxi 214023, China

Full list of author information is available at the end of the article

(c) The Author(s). 2020 Open Access This article is distributed under the terms of the Creative Commons Attribution 4.0 International License (http://creativecommons.org/licenses/by/4.0/), which permits unrestricted use, distribution, and reproduction in any medium, provided you give appropriate credit to the original author(s) and the source, provide a link to the Creative Commons license, and indicate if changes were made. The Creative Commons Public Domain Dedication waiver (http://creativecommons.org/publicdomain/zero/1.0/) applies to the data made available in this article, unless otherwise stated. 


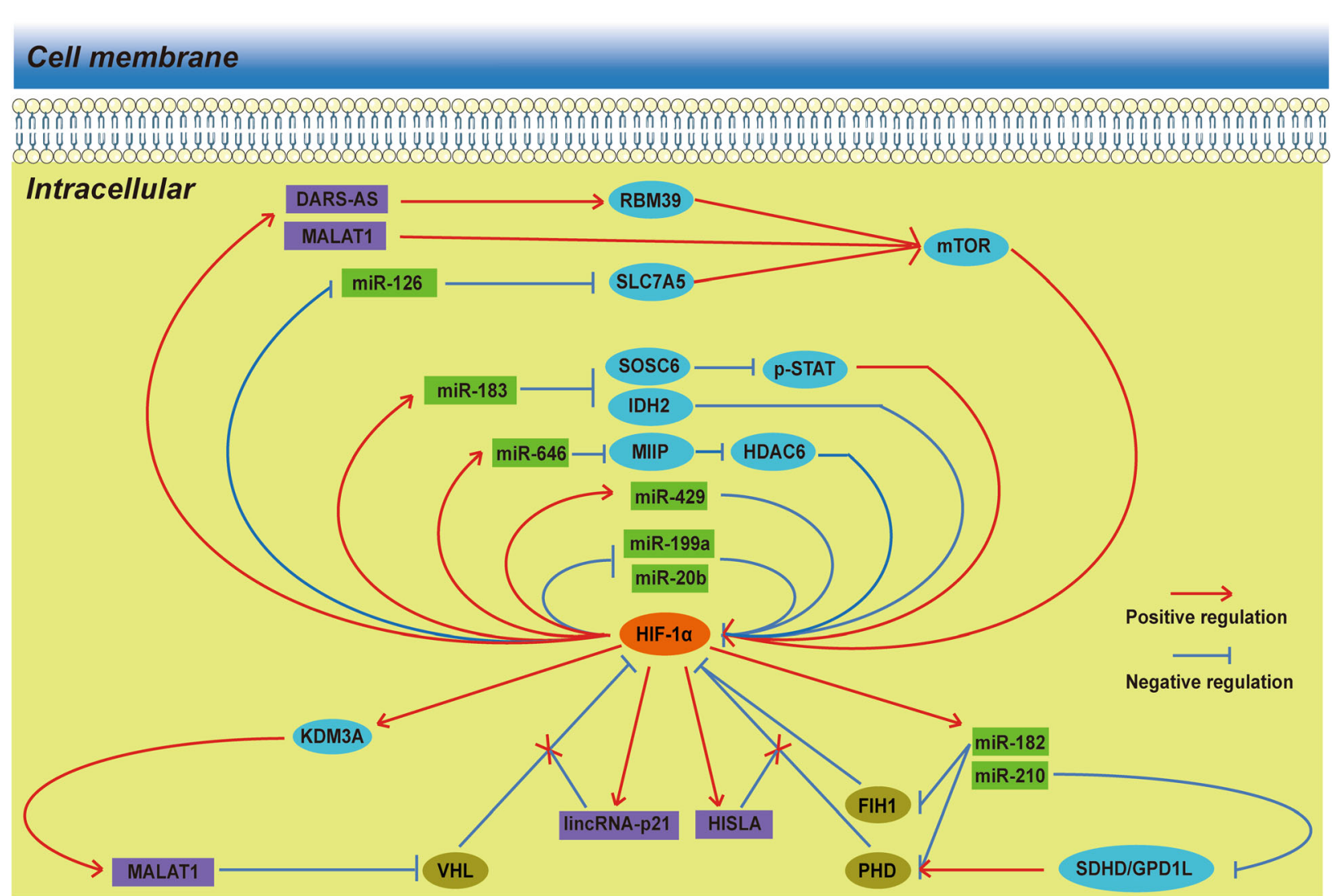

Fig. 2 Reciprocal feedback loops between HIF-1a and ncRNAs. In addition to a unidirectional regulation pattern, there are several direct or indirect feedback loops between HIF-1a and ncRNAs. It seems quite feasible that the ncRNAs, HIF-1a and other co-operators would eventually intertwine to form mutually reciprocal feedback loops in both positive and negative manners. In addition to common feedback loops, lincRNAp21 and HISLA can block VHL- and PHD-dependent HIF-1a repression instead of directly interacting with HIF-1a and other co-operators 